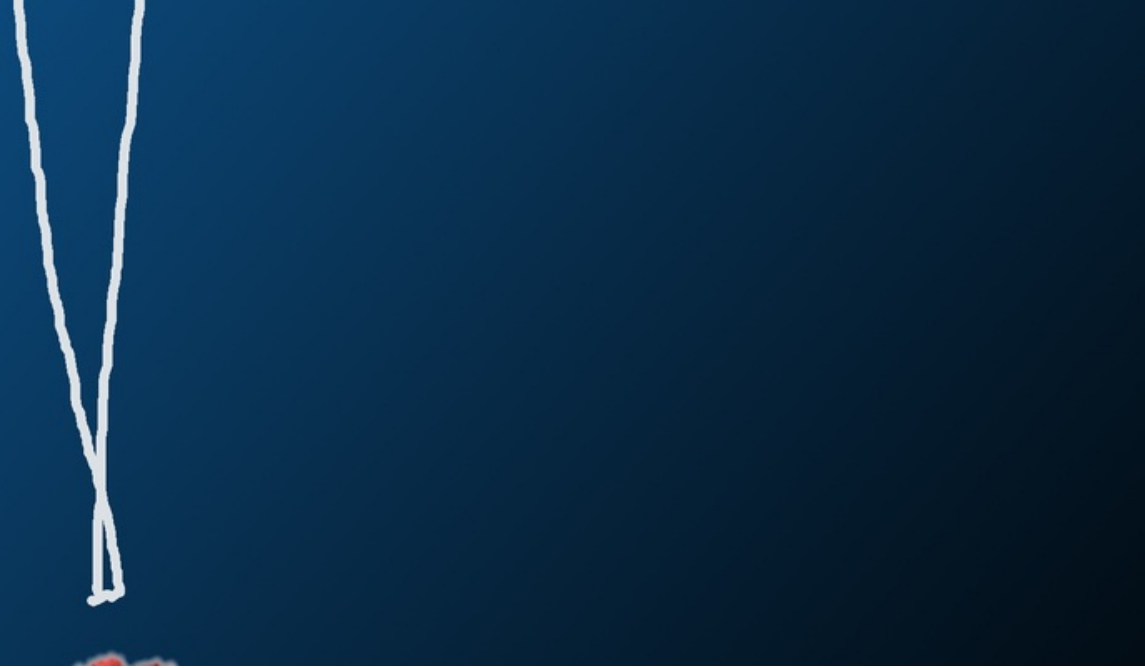

\title{
COVID-19 in Kosovo: Point from an Urbanite
}

$\begin{aligned} \text { Authors: } & \text { Bujar Q. Bajçinovci, Mejreme Bajçinovci } \\ \text { Submitted: } & \text { 21. June } 2020 \\ \text { Published: } & 29 . \text { June } 2020 \\ \text { Volume: } & 7 \\ \text { Issue: } & 3 \\ \text { Affiliation: } & \text { University of Prishtina, Faculty of Civil Engineering and } \\ & \text { Architecture, Kosovo. } \\ \text { Languages: } & \text { English } \\ \text { Keywords: } & \text { COVID-19, Kosovo, Urbanite, Public Health, Lifestyle } \\ \text { Categories: } & \text { News and Views, Visual Arts, Architecture and Design } \\ \text { DOI: } & 10.17160 / \text { josha.7.3.685 }\end{aligned}$

Abstract:

In the continuum of evolution and adaptation of living organisms, ranging from microorganisms to human beings, there are certain cycles of time that carry with its cardinal changes that human beings must face and find the possible public health solutions. The new millennium brings with it a new public health, and public order issues, thus, manifestation completely a new urban lifestyle. Therefore, we have come into a situation where a number of questions need to be raised about the necessity of redefining many daily life habits. The comments presented in this paper investigated the COVID-19 phenomenon in Kosovo, from urbanites point of view, where to many urban habits and lifestyle are being radically changed in the front of new contagious disease. Focusing on the urban lifestyle, public health, public order, high education, and possible urban depressions related to the quarantine conditions. How we came in this situation in first place! Affecting the entire globe in a month-s! From the middle of the March, when new Public Health measures has been started, Kosovars has reacted with great awareness and discipline, thus, contributing to the Public Health and Public Order wellbeing, never seeing this discipline before. The current, and possible future state of Public Health in Kosovo are more or less as the pandemic situation of the Balkans.

\section{JOSHA Jumana ostancea Humanities and Arts}




\title{
COVID-19 in Kosovo: Point from an Urbanite
}

\author{
Bujar Bajçinovci ${ }^{1}$, Mejreme Bajçinovci ${ }^{2}$ \\ ${ }^{1}$ University of Prishtina, Faculty of Architecture, Kosovo. \\ ${ }^{2}$ National Institute of Public Health, Prishtina, Kosovo. \\ Email:_bujar.bajcinovci@uni-pr.edu,.mejreme.bajcinovci@uni-pr.edu
}

\begin{abstract}
:
In the continuum of evolution and adaptation of living organisms, ranging from microorganisms to human beings, there are certain cycles of time that carry with its cardinal changes that human beings must face and find the possible public health solutions. The new millennium brings with it a new public health, and public order issues, thus, manifestation completely a new urban lifestyle. Therefore, we have come into a situation where a number of questions need to be raised about the necessity of redefining many daily life habits. The comments presented in this paper investigated the COVID-19 phenomenon in Kosovo, from urbanites point of view, where to many urban habits and lifestyle are being radically changed in the front of new contagious disease. Focusing on the urban lifestyle, public health, public order, high education, and possible urban depressions related to the quarantine conditions. How we came in this situation in first place! Affecting the entire globe in a month-s! From the middle of the March, when new Public Health measures has been started, Kosovars has reacted with great awareness and discipline, thus, contributing to the Public Health and Public Order wellbeing, never seeing this discipline before. The current, and possible future state of Public Health in Kosovo are more or less as the pandemic situation of the Balkans.
\end{abstract}

Key words: COVID-19, Kosovo, Urbanite, Public Health, Lifestyle.

\section{INTRODUCTION}

"In the continuum of evolution and adaptation of living organisms, ranging from microorganisms to human beings, there are certain cycles of time that carry with its cardinal changes that human beings must face and find the best possible public health solutions. The daily challenges must stimulate new scientific research and crucially need to be directed at utilizing all the medical resources, above all, the public health wellbeing. The new millennium brings with it a new public health, and public order issues, thus, manifestation completely a new urban lifestyle, as a result of a number of health, and determining factors, driven by science, technology, and the phenomenon of globalization" [1]. Therefore, we have come into a situation where a number of questions need to be raised about the necessity of redefining many daily life habits, especially in personal hygiene. Nowadays, globally, urban life endures a major challenge, as a result of evident climate change, 
as well as completely new diseases, furthermore, globalization is described as a process in which regional economies, societies and cultures integrate through a global network of political ideas, communication, transport and integral value of the global market. The phenomenon of globalization is an unstoppable historical process that reflects with relevant technological innovations, science, new economic, ecological strategies, and finally public health issues [1]. The new situation of global public health state is crystal clear, and, 'finally we are aware', that the World is one truly Ecumenopolis, where problems and solutions are interlinked wide holistically, moreover, health solutions emphasizes the need to create efficient global health strategies reflecting to the World as a one big city. "Cities are complex ecosystems with specific phenomenon's directly reflected in our health, natural resources, economic, social and aesthetic fields. They are open integrated systems and huge organisms with specific and complex metabolism that transform vast amount of energy, generate huge amount of waste and emanate a number of specific environmental phenomenon's and health activities" [2].

\section{MATERIALS and METHODS}

The comments presented in this paper investigated the COVID-19 phenomenon in Kosovo, from urbanites point of view, where to many urban habits and lifestyle are being radically changed in the front of new contagious disease. Focusing on the urban lifestyle, public health, public order, high education, and possible urban depressions related to the quarantine conditions. The comments consist of empirical observation through urban zones, interviews, government documents, and literature review. In order to perceive a clearer data, the observation is made within spatial regulation, municipality actions, focusing on the environment and the affected regions. The data collected include maps, composition of urban zones, attributes of the environment, dimensions of the urban regions. The additional data for this paper is based on the right understanding of legacy for future generations, which consists in the fact that we are interdependent with the demand for public health wellbeing and the empowerment of possible alternatives in preserving the ecosystem for the future. We have genuine examples from historiography of past civilizations and their 


\section{JOSHA}

Journal of Science, Humanities and Arts

disappearance as a phenomenon of depletion of the essential resources needed for living. Therefore, the approach and thinking that this phenomenon will not happen to another generation rather than the current one, creates a false reality, as the entire ecosystem is in direct interaction and dependence of past, present, and the future [1]. The trend of globalization is an unstoppable historical process that will reflect on new technologies, science and evolutionary urban strategies. In the last decade, globalization has become a promoter of development, engaging in social development with a dose of 'loss of identity' and the characteristics of local environment? Hence, there is a general consensus that regional and local identity will play an important role in the continuity of the diversity of culture and ethnological attributes, in which local and community identity is maintained [1].

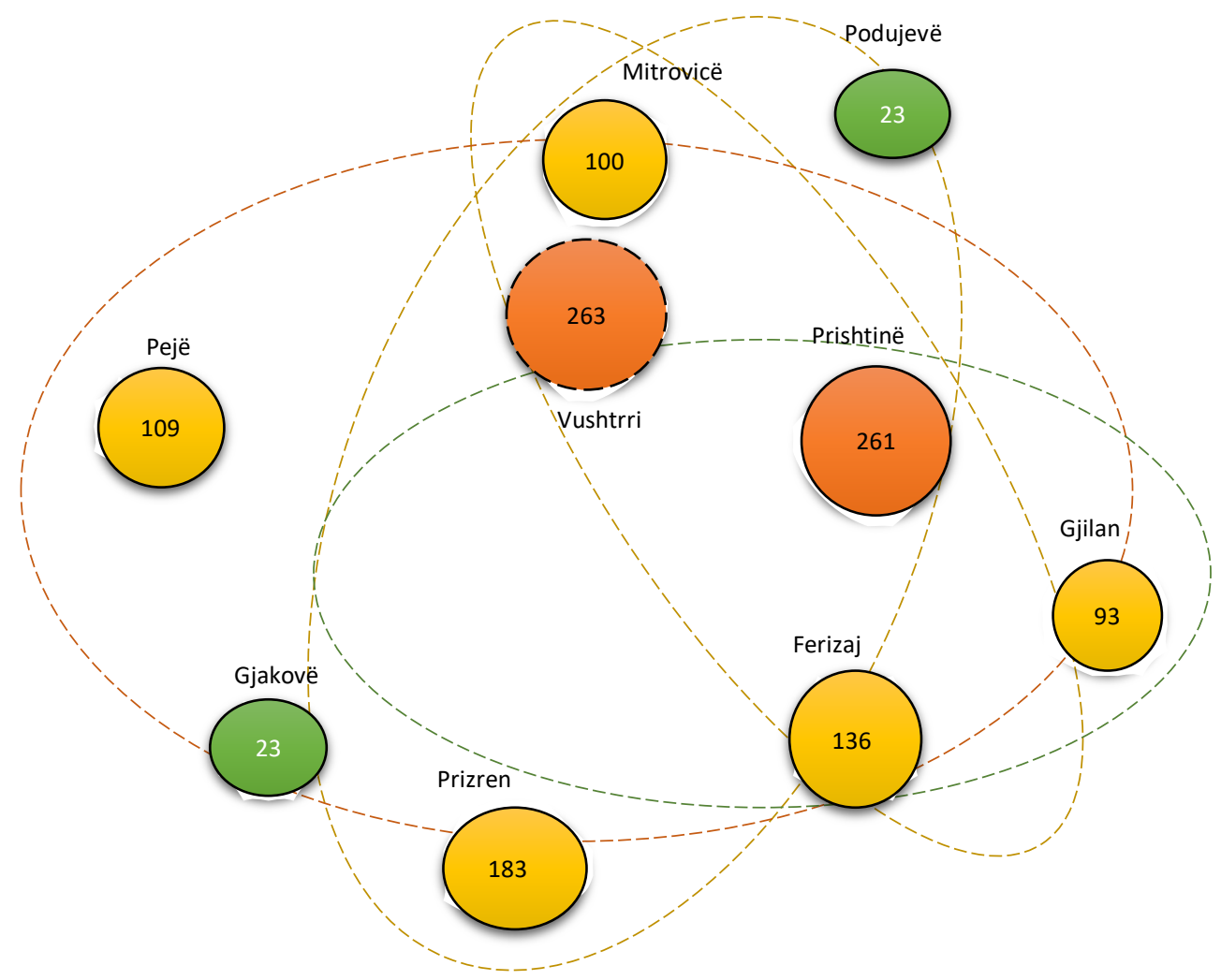

Figure 1. COVID-19 cases in Kosovar Cities, graphically presented as map. (June 16, 2020) Source: National Institute of Public Health of Kosovo 
The feeling that we belong to something, as part of the umwelt, and whole universe, these are the elements and features of the new implementation of global wellbeing, as well as World public health. The new millennium will bring fundamental life, and health situations, which call into question the necessity of redefining many our habits, and lifestyle!

Table 1. COVID-19 cases: Globally, Kosovo, and Albania. (June 16, 2020)

Source: National Institute of Public Health of Kosovo

\begin{tabular}{l|c|c|c} 
COVID-19 & Infected & Healed & Deaths \\
\hline World & & & \\
\hline Kosovo & 8079076 & 3915347 & 438171 \\
\hline Albania & 1756 & 968 & 34 \\
\hline
\end{tabular}

\section{DISCUSSION}

Actually, infection with SARS-CoV-2, the virus that causes COVID-19, can cause disease ranging from mild to severe, and in some cases can be fatal. Symptoms usually include fever, cough, and difficulty breathing. The disease may be manifested by other symptoms such as those of gastrointestinal infection. Also, the person may be asymptomatic but infected with COVID-19. According to the WHO and the CDC, COVID-19 symptoms may appear from 2 to 14 days after exposure [3]. Since the middle of the March, Kosovo has taken the most necessary health measures, such a quarantine, for the infected individuals, also for the districts, and specific cities. Those measures have been backed up, from the awareness of the modest capacities of health care system service, to treat this specific disease. Completely new situation in medication knowledge. Surely, in the beginning we have heard and seen the confusion of the medical personnel arguing which drugs to prescribe to the patients! Even now we are mostly in the same situation! Which drugs are most effective, and finally, when will come the most needed vaccine! 
From the point of the Kosovar urbanites, there are crucial questions, which are more effective: new specific drugs or vaccine, and when will be available! From middle of the March, when new Public Health measures has been started, Kosovars has reacted with great awareness and discipline, thus, contributing to the Public Health and Public Order wellbeing, never seeing this discipline before. University of Prishtina, where we booth teach, have 42,006 students, and 900 members of the academic staff. This unity of academia, have started with a great enthusiasm and beginning the first steps of virtual teaching without prior serious practice. Actually, the spring semester have been finalized with great results as per opinion of the authors. Moreover, we have noticed a rise of academic interest and great efforts from Kosovar students to overcome this pandemic situation, and finally to breakthrough this nightmare with coming summer!

\section{CONCLUSION}

The current and possible future state of Public Health in Kosovo are same as the pandemic situation of Balkan States. Moreover, actually there is no known effective treatment, and available effective vaccine. In the daily basis the health measures are loosen and relaxed. Hence, evidencing from experts that the second wave of COVID-19 are expected in autumn! How we came in this situation in first place! Affecting the entire globe in a month-s!

"Crisis is what suppressed pain looks like; it always comes to the surface. It shakes you into reflection and healing. " Bryant McGill

\section{REFERENCES}

[1] Bajçinovci, Q. B., Bajçinovci, B., Bajçinovci, U. (2020) Architectural Design Process: Consulting with Nature. Journal of Science, Humanities and Arts. Volume 7, Is. 2. DOI: 10.17160/josha.7.2.643

[2] Bajçinovci, B., Jerliu, F. (2016). Challenges of Architectural Design in relation to Environment and Air Pollution. A Case study: Prishtina's first public parking garage. Journal of Science, Humanities and Arts. Volume 3, Is. 7. DOI: 10.17160/josha.3.7.254

[3] RKS. Ministry of Health, National Institute of Public Health of Kosovo. (2020). Temporary Guidelines of Measures for Prevention and Fighting Covid-19 In Public and Private Institutions. 